\title{
A One Health framework for integrated service delivery in Turkana County, Kenya
}

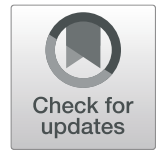

\author{
Evan F. Griffith ${ }^{1 *} \mathbb{D}$, Job Ronoh Kipkemoi ${ }^{2}$, Alison H. Robbins ${ }^{1}$, Tequiero O. Abuom ${ }^{3}$, Jeffrey C. Mariner ${ }^{1}$,
} Tabitha Kimani ${ }^{4}$ and Hellen Amuguni ${ }^{1}$

\begin{abstract}
Pastoralists in sub-Saharan Africa have limited access to public services due to their mobile lifestyle, economic and political marginalization, and the limited health infrastructure that is common to arid and semi-arid lands (ASALs) where they primarily reside. This often results in poor health outcomes, including increased rates of maternal, neonatal, and under-5 mortality. One Health approaches that integrate human and animal health service delivery can help to improve pastoralists' health through increased vaccine coverage and improved access to services. Kenya has institutionalized One Health at the national level; however, progress at the subnational level has been limited due to sustainability concerns, competing priorities, and insufficient coordination platforms. To address this gap, this paper presents a One Health framework (OHF) to aid in the implementation of integrated human and animal health policies in Turkana County, which can act as a model for other ASALs. Utilizing a grounded theory design, we conducted semi-structured interviews and focus group discussions with human health, animal health, and pastoralist stakeholders. Inadequate engagement with the public sector was identified as a major limitation by community members. Factors that contributed to this include distance to health facilities and restricted department capacities such as availability of vehicles, personnel, and cold chain maintenance.

Our proposed OHF harnesses the existing structure of service delivery in Turkana and establishes an official coordination mechanism to implement One Health activities, through the form of mobile "One Health Huduma Centres", offering a range of public services. This innovative framework is supported by stakeholders in Turkana and can improve service delivery constraints thereby improving the health of Turkana pastoralists.
\end{abstract}

Keywords: One Health, One Health framework, One Health Huduma Centre, Turkana County, Integrated service delivery, Grounded theory

\section{Introduction}

Pastoralists, who primarily raise livestock in arid and semi-arid lands (ASALs) and rely on strategic mobility to access grazing and water resources, play an important socioeconomic role in sub-Saharan Africa. An estimated 268 million pastoralists in Africa contribute between 10 and $44 \%$ to their country's gross domestic product (Zoonotic Disease Unit 2013). Pastoralists are politically and economically marginalized, often lacking access to the

\footnotetext{
* Correspondence: evan.griffith@tufts.edu

${ }^{1}$ Cummings School of Veterinary Medicine, Tufts University, North Grafton, USA

Full list of author information is available at the end of the article
}

basic services available to more settled populations (Zinsstag et al. 2006). ASALs are geographically vast with poor road networks, communication and electricity infrastructure, contributing to this lack of access. In addition, due to their mobility, pastoralists are difficult to reach with conventional health delivery systems. This problem is compounded by financial, logistical, and service delivery constraints in the public health and veterinary sectors (Schelling et al. 2007). As a result, many pastoralist communities suffer from poor health compared to national averages (Zinsstag et al. 2015).

Pastoralists in East Africa are particularly at higher risk of zoonotic diseases, such as echinococcosis, rabies, 
brucellosis, bovine tuberculosis, and Rift Valley fever (RVF) due to their livestock keeping practices, consumption of animal source foods (e.g. drinking raw blood or milk), inadequate access to treatment, and living in harsh environmental conditions (Mangesho et al. 2017; Zinsstag et al. 2016; Desta 2016). In addition to their own health, pastoralists are greatly affected by the health of their livestock, upon which their livelihoods depend. Thus, livestock diseases that are prevalent in African pastoral regions, such as foot and mouth disease (FMD), Peste des petits ruminants (PPR), RVF, and contagious caprine pleuropneumonia (CCPP), threaten their livelihoods (Zinsstag et al. 2016).

In Kenya, ASALs occupy over $80 \%$ of the country's landmass and hold $36 \%$ of the human population, $70 \%$ of the national livestock, and $90 \%$ of wildlife (Barrow and Mogaka 2007; Schilling et al. 2012). As of 2012, Kenya's ASALs contained an estimated 13 million cattle, 25 million goats, 14.9 million sheep, 1.7 million donkeys, and 2.9 million camels (Schilling et al. 2012). These areas are characterized by marked variability in rainfall both spatially and temporally within and between years (African Union 2013).

Turkana is one of the ASAL counties in Kenya that has a primarily nomadic population. The system of governance in Turkana comes from the Constitution of Kenya (2010), which established a new system of county-based, decentralized government (i.e. devolution), which holds the responsibility for basic service delivery, including health services.

In Turkana County, information sharing and activity planning occur between various government departments and non-governmental organizations (NGOs) at the County Steering Group (CSG). The CSG is a coordination forum co-chaired by the county government and commissioner-hence bringing together two levels of government. Independently, each department is led by a county executive council member and chief officer.
In Turkana, veterinary services fall under the Ministry of Agriculture, Pastoral Economy and Fisheries and are primarily mobile, as bricks-and-mortar veterinary clinics and hospitals do not exist in Turkana. In contrast to veterinary services, human health services are based on existing health infrastructure and, thus, are not mobile in nature, except in isolated cases when NGOs or the government carry out mobile outreaches. The Department of Preventative and Promotive Health (DPPH), which falls under the Ministry of Health and Sanitation, is response for all public health programming. Roles of veterinary and public health personnel and local leaders in public health and animal health activities can be found in Table 1.

While the Turkana Government is primarily responsible for providing public services, NGOs assist in service delivery and disease surveillance in the human and animal health sectors. Often, county officials will plan activities and NGOs will provide monetary and logistical support. This coordination happens at the CSG.

In 2018, there were 13 hospitals, 19 health centres, 194 dispensaries, and 136 functional community health units (CHUs) in Turkana, with the average distance to the nearest facility of $35 \mathrm{~km}$ (Department of Health and Sanitation Services 2018). While this shows significant improvement on the infrastructure and human resources of health domains in Turkana since devolution, health facilities are still limited in Turkana. In comparison with the Kenya Essential Package for Health (KEPH) national norms and standards based on population, Turkana has a total deficit of 20 health facilities and 96 CHUs, with existing facilities skewed towards urban areas (Department of Health and Sanitation Services 2018).

In addition, health indicators are still below the national average. For example, maternal mortality rate (per 100,000 births) is 1594 compared to 362 nationally, neonatal mortality rate (per 1000 births) is 80 compared to

Table 1 Government personnel and local leaders involved in public health and animal health activities in Turkana County

\begin{tabular}{|c|c|c|}
\hline & Personnel & Role \\
\hline \multirow[t]{2}{*}{ Directors (county) } & County director of veterinary services (CDVS) & $\begin{array}{l}\text { Disease and vector control activities, veterinary public health } \\
\text { activities }\end{array}$ \\
\hline & $\begin{array}{l}\text { Director of preventative and promotive health } \\
(\mathrm{DPPH}) \text {; Deputy director (DD) }\end{array}$ & Preventive and promotive health service programmes \\
\hline \multirow[t]{4}{*}{$\begin{array}{l}\text { Implementors } \\
\text { (subcounty/ward/village) }\end{array}$} & $\begin{array}{l}\text { Subcounty veterinary officer (SCVO); Livestock } \\
\text { health officer }(\mathrm{LHO})\end{array}$ & $\begin{array}{l}\text { Vaccination implementation, treatment, surveillance, livestock } \\
\text { movement control, and laboratory diagnosis }\end{array}$ \\
\hline & Community disease reporter (CDR) & $\begin{array}{l}\text { Symptomatic disease surveillance, assist with implementation of } \\
\text { activities }\end{array}$ \\
\hline & Subcounty public health officer (SCPHO) & Management and coordination of public health services \\
\hline & $\begin{array}{l}\text { Community health unit (CHU): one community } \\
\text { health extension worker (CHEW), 1+ community } \\
\text { health volunteer (CHV) }\end{array}$ & $\begin{array}{l}\text { Basic community health services (health promotion, disease } \\
\text { prevention, first aid, community disease surveillance, } \\
\text { mobilization for immunization, and referral) }\end{array}$ \\
\hline \multirow[t]{2}{*}{ Local leaders } & Emuron & Entry point to a community \\
\hline & Chief/subchief & Report disease events; mobilize communities for outreach activities \\
\hline
\end{tabular}


22 nationally, and under 5 mortality rate (per 1000 births) is 74 compared to 52 nationally (Department of Health and Sanitation Services 2018).

Livestock play a critical role in the livelihoods of pastoralists. They are also an important national commodity in Kenya, with pastoral meat providing $28 \%$ of total consumption with an estimated value of 0.389 billion USD (Nyariki and Amwata 2019). Infectious diseases pose a serious threat to these livestock. For example, the 2007 PPR outbreak caused an estimated 19.1 million USD in losses in Turkana and spread out to other ASALs in Kenya (FAO 2009; Kihu et al. 2015a). In 2015, the PPR seroprevalence in Turkana was estimated at $40 \%$ and $32 \%$ in goats and sheep, respectively (Kihu et al. 2015b). Similarly, the CCPP seroprevalence was recorded at 63.9\% in Turkana West subcounty (Kipronoh et al. 2016). More recent estimates of relative prevalence are $17 \%$ and $13.3 \%$ for CCPP and PPR, respectively (Veterinary Services 2019). A study in 2019 found the average annual economic loss due to CCPP for a standard flock of 100 goats in Turkana was 1712.66 euros, equivalent to 1,932.99 USD (Renault et al. 2019). These and other endemic livestock diseases, such as helminths, haemorrhagic septicaemia, and tick-borne infections, threaten pastoral livelihoods in Turkana. Thus, there is a serious need to improve human and animal health service delivery in Turkana.

One Health approaches to health service delivery hold the potential to address these gaps. At its core, One Health is rooted in understanding the interdependence of human and natural systems, and can be defined as integrative effort of multiple sectors working to attain optimal health for people, animals, and the environment, involving different collaborative models across and within countries, with the aim of improving efficiency and effectiveness in managing health threats (Vesterinen et al. 2019). Additionally, Zinsstag et al. (2011) define One Health as any added value in terms of human and animal health, financial savings, or environmental benefit from closer cooperation of human and animal health sectors at all levels of organization.

One Health service delivery for nomadic pastoralists has demonstrated to be successful in other contexts. Joint human-livestock vaccination has reduced total costs for veterinary and public health departments through shared transport, logistics, and equipment, while increasing vaccination coverage among pastoralist children (Schelling et al. 2007; Ward et al. 1993; Bomoi et al. 2016; Abakar et al. 2016). A One Health combined delivery platform for Maasai pastoralists combined mass drug administration for soiltransmitted helminths in humans and mass dog rabies vaccination in Tanzania. This approach was highly regarded among the community and saved costs and time (Lankester et al. 2019). In Uganda, the integration of vaccination and health education to combat brucellosis was perceived by pastoralists and health service providers as feasible and desirable (Kansiime et al. 2015). In addition, mobile clinics are a more suitable method of service delivery for pastoralists and often more cost-effective, as they mirror their nomadic lifestyle (El Shiekh and van der Kwaak 2015; Weibel et al. 2008; Mocellin and Foggin 2008). Thus, integrated, mobile service delivery can improve pastoralist health. In order to implement this approach, new coordination mechanisms and health system infrastructure in ASALs is needed (Kansiime et al. 2015).

Efforts to institutionalize One Health in Kenya have been guided by two policies: the Kenya Health Policy (KHP; 2012-2013) and the Kenya Veterinary Policy (KVP; 2016). The KHP recognized the need for collaboration with other sectors whose functions impact human health, which can be achieved by adopting a One Health approach (Ministry of Health 2014). The KVP expanded on this approach that espouses inter-disciplinary cooperation for successful intervention in matters that affect human, animal, and environmental health. It called for the establishment of collaborative platforms at the national and county levels, in partnership with stakeholders, for managing zoonotic disease events and other animalbased hazards to public health (Ministry of Agriculture, Livestock and Fisheries, Republic of Kenya 2015).

These efforts have been generally successful at the national level, notably through the efforts of the Zoonotic Disease Unit (ZDU). The ZDU has provided an institutional body to address One Health issues of concern (e.g. zoonoses, antimicrobial resistance) through capacity building, research, workforce development, and coordinated investigation and outbreak response (Munyua et al. 2019). The expansion of One Health at the subnational level has mainly consisted of the ZDU and partner organizations setting up county One Health units to enhance communication between health and livestock sectors to address zoonotic diseases. While adoption of One Health at the national level is significant, more progress is needed at the county and subcounty levels. Challenges include sustainability, competing interests, and a lack of coordination platforms (Munyua et al. 2019; Kimani et al. 2016). Further, One Health policy can do more to address the specific challenges of service delivery constraints experienced by pastoralists.

Through semi-structured interviews (SSIs) and focus group discussions (FGDs) with stakeholders and an appraisal of the current human and animal health services in Turkana County, this study sought to develop a One 
Health framework (OHF) to aid in the implementation of One Health policy in Turkana.

\section{Study area}

Turkana County is one of the largest counties located in the northern frontier of Kenya. It is situated within the Karamoja Cluster, a region along the borders of Kenya, Ethiopia, South Sudan and Uganda that is primarily inhabited by pastoralists. Turkana is bordered by West Pokot and Baringo Counties to the south, Samburu County to the south-east, and Marsabit County to the east (Fig. 1). Internationally, it borders Uganda to the west, South Sudan to the north, and Ethiopia to the north-east (Fig. 1). It is $77,000 \mathrm{~km}^{2}$ in total area. Administratively, Turkana
County is divided into seven subcounties and 30 wards. The human population of Turkana County is 926,976 (Kenya National Bureau of Statistics 2019). Livelihoods in Turkana consist of $60 \%$ pastoralism, 20\% agropastoralism, $12 \%$ fisheries, and $8 \%$ wage employment and others, with livestock providing the main source of food and cash income for $80 \%$ of the population in Turkana (Tullow Oil 2017). Goats and sheep make up the largest livestock populations in Turkana, with 5,994,881 and 3, 519,148 , respectively (Kenya National Bureau of Statistics 2010). According to the 2010 census, there were: 1,534, 612 cattle, 832,462 camels, 558,189 donkeys, 165,349 indigenous poultry, and 15,449 commercial poultry in Turkana County (Kenya National Bureau of Statistics 2010).

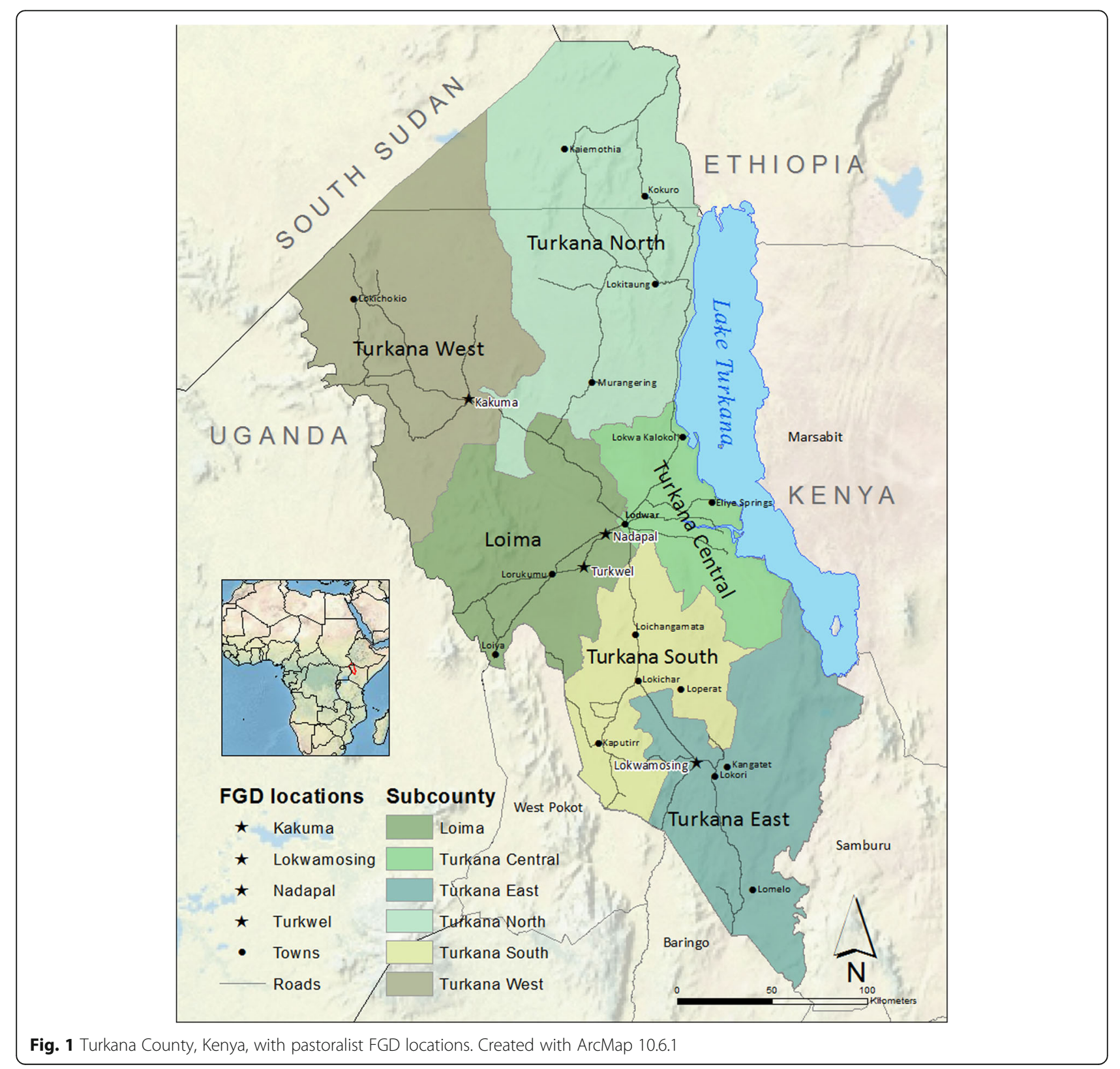




\section{Methods}

\section{Study design}

This qualitative study consisted of SSIs and FGDs with officials in the human and animal health sectors and with community pastoralists. We used a grounded theory (GT) approach throughout the design and analysis phases of the project. Notably, we designed data collection tools based on preliminary research and knowledge on human and animal health concerns in Turkana, conducted concurrent data collection and analysis, created codes and categories based on preliminary emergent themes, and analysed data based on thematic saturation (Charmaz and Belgrave 2007). The study protocol, SSI, and FGD interview guides were submitted to and received approval from the Tufts University Institutional Review Board. Verbal consent was obtained following an explanation of the project's objectives and procedures, and human subject considerations were taken into account prior to conducting all SSIs and FGDs. COnsolidated criteria for REporting Qualitative research (COREQ) were followed to enhance transparency and credibility (Tong et al. 2007).

SSIs and FGDs with officials were conducted in English and each lasted approximately $60 \mathrm{~min}$. An interview guide was developed and tested in the field prior to study implementation. The guide included open-ended questions on department/organizational structure, vaccination protocols and challenges, intersectoral collaboration, integrated service delivery, perceived benefits of integrated service delivery, and recommendations for implementing integrated service delivery in Turkana County. Probes and follow-up questions were used to explore and clarify points raised by participants.

Following pilot testing, FGDs with pastoralists took place in private, centrally located areas and were conducted in the Turkana language and thereafter translated into English. FGDs lasted $60 \mathrm{~min}$ and included openended questions on human and animal healthcare access and limitations, and perceptions on integrated service delivery.

Data saturation was reached when consensus and no new themes emerged. Interviews and FGDs were conducted over a 3-week period in August 2018. Audio recordings of each interview, transcripts, and field notes were stored in a password-protected cloud-based drive. Transcripts and field notes were analysed using NVIVO 12.

\section{Study sample}

SSI and FGD participants were recruited purposively from the following two groups:

1. Animal health sector, comprising government and NGO officials with knowledge of vaccination practices and mobile service delivery in Turkana County

2. Human health sector, comprising government and NGO officials with knowledge of vaccination practices and mobile service delivery in Turkana County

Recruitment was conducted in person, by telephone, or by email. SSIs were conducted with animal health and human health government and NGO officials. FGDs were conducted with public health officials and NGO officials. Further information on participant composition can be found in Table 2.

FGDs with pastoralists were conducted in four locations throughout Turkana County (Fig. 1; Table 3). Subcounty locations were selected randomly, while villages/towns were purposefully sampled to get diverse experiences and perspectives from respondents closer to towns (Nadapal and Turkwel), away from towns (Lokwamosing), and close proximity to refugee camps (Kakuma). Participants from each location were selected using convenience sampling based on availability. Equal representation of male and female participants was prioritized and achieved when possible.

\section{Data analysis}

Following the first round of interviews and routinely throughout the study, we iteratively developed a list of codes that encompassed emergent major and minor themes. Initially, this consisted of open coding to develop concepts and categories. Axial coding was used to identify the relationship between open codes. Finally, selective coding was used by relating developed codes to the core concept of integrated service delivery. A schematic of the resulting OHF was built using Creately, an online diagramming tool. During the coding process, we

Table 2 SSIs and FGD with government and NGO officials in the human and animal health sectors

\begin{tabular}{ll}
\hline Sector & Personnel interviewed \\
\hline Animal health sector & SSIs: veterinary department leadership \\
& $(n=1) ;$ SCVOs $(n=4) ;$ LHO $(n=2)$ \\
Human health sector & SSIs: SCPHO $(n=2)$ \\
& FGDs: public health officials (one group, \\
& two participants) \\
& SSIs: Feinstein International Center \\
& $(n=1)$, Food and Agriculture Organization \\
NGOs & (FAO; $n=1)$, Luther World Federation \\
& $(n=1)$, Afya Timiza ( $n=1)$, Caritas (Catholic \\
& Diocese of Lodwar; $n=1)$, International \\
& Rescue Committee ( $n=1)$, Agency for \\
& Pastoralists Development ( $n=1)$ \\
& FGDs: Turkana Pastoralist Development \\
& Organization (one group, seven participants), \\
& Veterinary Sans Fronteir Germany (one group, \\
& two participants) \\
\hline
\end{tabular}


Table 3 Composition and location of FGDs with pastoralists

\begin{tabular}{ll}
\hline Location & FGD composition \\
\hline $\begin{array}{l}\text { Nadapal village, Loima subcounty, } \\
\text { Turkwel ward }\end{array}$ & Two woman, three men \\
$\begin{array}{l}\text { Turkwel village, Loima subcounty, } \\
\text { Turkwel ward }\end{array}$ & Five men \\
$\begin{array}{l}\text { Kakuma town, Turkana West subcounty, } \\
\text { Kakuma ward }\end{array}$ & Seven men \\
Lokwamosing village, Turkana & Four women, six men \\
East subcounty, Kachodin/Kokori ward & \\
\hline
\end{tabular}

used field and coding memos to develop thoughts and future directions.

Coding was performed by one primary coder, and coded transcripts were routinely reviewed by the study co-authors to ensure consistency throughout. Any disagreements in coding were resolved by consensus.

\section{Results}

\section{Intersectoral collaboration}

Interviews with government officials provide evidence of several existing intersectoral collaborations between the human and animal health sectors. These include meat inspection, rabies control, zoonotic disease extension services, and subcounty officer meetings.

It was reported that rabies control activities are shared among veterinary and human health officials. Veterinarians carry out dog baiting for stray dogs and cats and sterilization procedures for population control, while public health officers are in charge of disposing of dog carcasses via burial. There are also examples of informal disease reporting and case finding (e.g. animal health official inquiring about rabies cases at a health centre). Collaboration also occurs during livestock vaccination campaigns with public health officials disposing of waste such as syringes.

The results showed that intersectoral extension, or human and animal health officials educating community members together about zoonotic disease, also occurs. For example, in Turkana West, veterinary and human health officials will conduct these types of outreaches together on an ad hoc basis.

In Loima subcounty, the subcounty veterinary officer (SCVO), subcounty public health officer (SCPHO), and subcounty environmental officer meet on a quarterly basis, or in the event of disease outbreak event, to better coordinate disease surveillance and outbreak response. Subcounty officials noted this has proven to be an effective measure to quickly respond to disease outbreak events.

Another example of the One Health approach is The Kimormor Program. Participants noted that this programme is run by Afya Timiza, an NGO funded by the United States Agency for International Development
(USAID), and uses integrated service delivery (i.e. preventative and curative human and animal health services, provision of national identification cards and birth certificates, sign-up campaigns for the National Hospital Insurance Fund (NHIF), and provision of services provided by the National Drought Management Authority) to improve immunization coverage and access to public services. Observed benefits of this programme, according to an Afya Timiza official, include increased turnout and resulting increases in immunization coverage and reducing the distance that pastoralists in Kibish subcounty have to travel for services.

Finally, the CSG has previously planned and implemented integrated service delivery activities. For example, in 2014, Kenyan and Ugandan human and animal health officials treated pastoralists and livestock in Kotido, Kaabong, and Moroto Districts in the Karamoja region of Uganda. Noted benefits from Turkana officials who participated directly included improved access to services, zoonotic disease extension, and use of services as a "peace dividend", resulting in an improvement in relationships between the Karamojong and Turkana peoples.

\section{Human and animal healthcare limitations}

Limited engagement with the public sector, due to distance to health facilities and insufficient veterinary personnel, was identified by community members as barriers to receiving services (Table 4). In addition, the

Table 4 Limitations of human and animal healthcare identified by pastoralists in FGDs

\begin{tabular}{|c|c|c|c|c|}
\hline \multirow[t]{2}{*}{ Theme } & \multicolumn{4}{|l|}{ Location } \\
\hline & Nadapal & Kakuma & Lokwamosing & Turkwel \\
\hline \multicolumn{5}{|l|}{$\begin{array}{l}\text { Limitations of human health } \\
\text { services }\end{array}$} \\
\hline $\begin{array}{l}\text { Distance to health } \\
\text { facilities }\end{array}$ & & & $\checkmark$ & $\checkmark$ \\
\hline $\begin{array}{l}\text { Insufficient funds to buy } \\
\text { drugs }\end{array}$ & & $\checkmark$ & & \\
\hline Drug shortages & & $\checkmark$ & & \\
\hline Poor quality & & $\checkmark$ & & \\
\hline Limited supply & $\checkmark$ & & & \\
\hline \multicolumn{5}{|l|}{$\begin{array}{l}\text { Limitations of animal health } \\
\text { services }\end{array}$} \\
\hline Insufficient time to treat & & $\checkmark$ & & \\
\hline Delayed response & & $\checkmark$ & & \\
\hline Limited veterinary staff & $\checkmark$ & & $\checkmark$ & \\
\hline $\begin{array}{l}\text { Insufficient funds to buy } \\
\text { drugs }\end{array}$ & $\checkmark$ & & & $\checkmark$ \\
\hline Fluctuating drug prices & & & & $\checkmark$ \\
\hline Drug shortages & $\checkmark$ & & $\checkmark$ & $\checkmark$ \\
\hline
\end{tabular}


availability and quality of drugs were also identified as limitations of health services.

\section{Vaccination challenges identified by human and animal health officials}

Officials identified a number of overlapping/common challenges associated with vaccination, which are summarized in Table 5. These included a lack of routine access to vehicles, inadequate cold chain maintenance, the nomadic lifestyle of pastoralists, and insufficient personnel to implement vaccination campaigns. Human health officials, for example, emphasized the commonality of defaulting from vaccination programmes, i.e. when vaccination schedules are not completed, as a result of the nomadic lifestyle. Difficulty in mobilizing communities for outreach activities directly contributes to defaulting.

Veterinary officials also described several examples of cultural norms and practices that affect pastoralists' involvement in animal vaccination activities. For instance, they noted a common perception among pastoralists that livestock should not be vaccinated during the dry season, when animals are in their poorest body condition. Veterinary officials refer to this as "resistance" to vaccination. Strategies identified to overcome this include adding value to vaccination services by deworming and using pour-on insecticides. One deputy subcounty veterinary officer described that providing medications increased motivation for vaccination: "sometimes you tell them, if you do not accept the vaccines, I will not give you the drug."

Human health officials emphasized that health centres located at far distances from community members reduce vaccine uptake. Pastoralists will often opt for traditional medicine rather than travel to these centres. This

Table $\mathbf{5}$ Challenges of vaccination identified by officials in the human and animal health sectors through SSIs and FGDs

\begin{tabular}{lll}
\hline Theme & \multicolumn{2}{l}{ Sector } \\
\cline { 2 - 3 } & Human health & Animal health \\
\hline Challenges of vaccination & & $\checkmark$ \\
Limited vehicles & $\checkmark$ & $\checkmark$ \\
Maintaining cold chain & $\checkmark$ & $\checkmark$ \\
Nomadic lifestyle & $\checkmark$ & $\checkmark$ \\
Insufficient personnel & $\checkmark$ & \\
Distance of health centres & $\checkmark$ & \\
from the community & & \\
Distance of communities & $\checkmark$ & $\checkmark$ \\
from town centres & & $\checkmark$ \\
Road infrastructure & & \\
Resistance to vaccination & & \\
Insecurity & &
\end{tabular}

supports what community members said in Lowkamosing and Turkwel (Table 4). Insecurity, caused by armed conflict between pastoral groups that restricts health service delivery activities, was mentioned by veterinary officials, but not human health officials. This reflects the fact that veterinarians carry out mobile campaigns and operate in border regions, while human healthcare is generally non-mobile and based on a fixed facility structure.

\section{Benefits of integrated service delivery identified by community members and service providers}

Interviewees and FGD participants identified multiple benefits of integrated service delivery that are summarized in Table 6. Both community members and service providers identified improved access to care and holistic care as a potential benefit of integrated service delivery. For example, in both Nadapal and Kakuma, participants highlighted that health service providers will go to communities located outside of town centres, reducing the distance required to travel to receive services. This would save on travelling resources. One community member in Nadapal said, "many people will get services, those people where you can't reach. They can just walk up on the day." In Kakuma, they also noted that human and animal health officials working together would improve the availability of both human and animal drugs, a noted limitation in care.

Several service providers mentioned improved access to care. Specifically, one subcounty public health officer said, "it will take services closer to the people and therefore, because people really move long distances, not only for health, but for other services, for example registry. They come for [national] identity cards. So, by moving closer to all these departments and services the community will not have to move."

Cost sharing between departments was identified by the majority of animal health and several human health

Table 6 Perceived benefits of One Health service delivery identified by service providers and pastoralists through SSIs and FGDs

\begin{tabular}{lll}
\hline Theme & \multicolumn{2}{l}{ Identified by whom } \\
\cline { 2 - 3 } & Service providers & Pastoralists \\
\hline Benefit to the community & $\checkmark$ & $\checkmark$ \\
Access to care & $\checkmark$ & $\checkmark$ \\
Holistic care & & \\
Benefit to service providers & $\checkmark$ & \\
Cost-sharing & $\checkmark$ & \\
Increased turnout & $\checkmark$ \\
Improved zoonotic disease extension & $\checkmark$ \\
Avoid duplication of services & $\checkmark$ \\
\hline
\end{tabular}


officials. They said it would help to overcome logistical limitations (e.g. vehicle and fuel costs) in each sector. One subcounty public health officer emphasized that "when Ministries pool resources, the impact will be much higher."

Improved mobilization of communities for outreaches was highlighted as a benefit by several animal and human health officials. Public health officers emphasized that increased turnout will help the departments reach their objectives (e.g. increasing immunization coverage). In addition, officials in both sectors identified the presence of livestock as the factor driving increased turnout. For example, a subcounty public health officer said, "when veterinary mobilizes, those who are interested in the animals vaccinated will come and the Ministry of Health will take advantage of such a population. There are people who we never reach [during] our outreaches. We are usually told they are gone, maybe to look for pastures elsewhere. So, such people will be available during the One Health approach."

A majority of animal health and a single human health official mentioned improved zoonotic disease extension as a benefit. They explained these diseases have animal and human components (e.g. transmission). Therefore, if human and animal health officials work together, the community will understand all aspects of the disease.

\section{Perceived challenges of implementing integrated service delivery}

Participants anticipated multiple challenges with integrated service delivery, including difficulties with coordination, limited time in the field, and the fact that livestock handlers, not the entire family, are found with livestock. Coordinating across Ministries is difficult, especially when outreaches are scheduled for different times. Coordinating activities also require planning by department heads. Integrated service delivery that includes health and public services will require a long time in the field. This was discussed as a challenge, because the longer these outreaches take, the more expensive they are. Finally, a veterinary officer mentioned that when they go to the field during the dry season, oftentimes, only adolescent herd boys or other relatives of the livestock owner accompany the animals. They cannot make the decision on whether the animals should be vaccinated or not, leaving them unvaccinated. Furthermore, if livestock owners and their families are not always with the livestock, they cannot be reached with other services during these times. However, another subcounty veterinarian noted that women or girls are usually present at watering points to water the livestock. Therefore, they suggested these areas can be targeted for integrated service delivery.
Suggestions for implementing integrated service delivery Participants provided suggestions on the structure, implementation, and mobilization of integrated service delivery in Turkana County. Several suggested One Health Committees (OHCs) should be created, composed of department directors and NGO officials at the county level and subcounty officers at the subcounty level. These committees would provide an official structure for cooperation at director and implementor levels, allowing for the actualization of integrated activities.

To coordinate activities, participants suggested that a shared work plan should be created by department directors and NGOs on the county OHC. Subcounty officers, in communication on the subcounty $\mathrm{OHC}$, should be in charge of implementing these work plans. They should communicate with local leaders, other officials, and administrators to carry out integrated service delivery.

Notably, participants described implementing integrated service delivery as a potential mobile "Huduma Centre", combining government human and animal health services. In Kenya, Huduma Centres offer government public services from a single location. Taking this one-stop shop for service approach, participants suggested that government officials and NGOs could travel together, delivering public services to remote parts of the county. This would not supersede current mobile delivery operations (e.g. veterinary vaccination campaigns), but instead be undertaken based on the needs of specific areas. In describing the advantages of this approach, one government official said, "[mobile, integrated service delivery] is more like devolution. It's a devolved function but delivered multifaceted at once. It's the Huduma centre that comes to the people."

Critical to integrated service delivery is mobilizing the community. The role of Emurons in mobilization was emphasized by several interviewees, who noted Emurons are critical in Kimormor as they identify how many kraals there are. These kraals are subsequently targeted for mobile delivery outreaches. Other officials also noted that chiefs are an excellent entry point to mobilize the community, because they are community authority figures who have established communication channels.

\section{Discussion}

\section{Proposed One Health framework}

Our results demonstrate that there already exists a coordination mechanism for One Health activities through the CSG and that intersectoral collaboration occurs as dictated by national law between veterinary and human health officials in Turkana County. For example, rabies control in Kenya is guided by the Rabies Act of 1967, revised in 2012 and now under revision as part of the One 
Health Strategic Plan for the Elimination of Human Rabies in Kenya 2014-2030 (Zoonotic Disease Unit 2014). The sharing of responsibilities in Turkana is in line with the national policy. However, what requires improvement is the formalization of information sharing/ reporting.

The limitations we identified in this study were primarily logistical and resource-based, highlighting the need for increased collaboration between government and NGO service providers. Furthermore, our results demonstrate that coordination among partners and the government is still inadequate in Turkana County, illuminating the need for an improved coordination structure. Our results support previous research on limitations of healthcare delivery to pastoral populations, including distance to health facilities and limited resources and logistical capacities of government departments (Zinsstag et al. 2006; Schelling et al. 2007). Thus, a mobile, integrated approach to service delivery can help to improve pastoralists' access to services in Turkana.

In order to overcome these limitations, we developed an OHF for integrated service delivery, which can act as an official coordination mechanism for One Health activities in Turkana County (Fig. 2). We suggest creating One Health Committees (OHCs) at the county and subcounty levels. The county $\mathrm{OHC}$ can help to coordinate government and NGO activities through a shared work plan. The subcounty OHC, made up of implementors, can then carry out these work plans. In addition, there is a need to formalize the intersectoral collaboration, especially in regard to disease reporting, happening among implementors at the subcounty level. The subcounty OHCs can also serve this purpose.

Further, we suggest that mobile, integrated service delivery in Turkana County takes the form of "One Health Huduma Centres" that offer human and animal health services; national identification cards; birth certificates; health insurance (NHIF); drought management services (NDMA); water, sanitation and hygiene (WASH) services; economic services; and other essential government services. Importantly, as integrated activities will be formalized through a shared work plan, any combination of these services can be delivered based on the current needs identified by government and NGO officials and community members. Thus, our proposed framework offers flexibility in addition to a formalized structure that facilitates intersectoral collaboration.

We present the OHF as an innovative approach to overcoming the limitations of public service delivery experienced by pastoralists in Turkana County. It will also institutionalize One Health at a subcounty level through an official coordination mechanism, which previous research has identified as lacking in Kenya, and is needed to implement integrated service delivery to pastoral communities (Kimani et al. 2016; Kansiime et al. 2015)
The OHF may increase access to services by bringing them to the people and, through resource sharing, overcome logistical changes identified by officials in the human and animal health sectors. Importantly, this approach incorporates all stakeholders to identify opportunities for joint service delivery and synergies in health service delivery through OHCs at the county and subcounty level. This is important when trying to improve health service delivery for pastoralists (Abakar et al. 2016).

\section{One Health in Turkana County}

Our study establishes that in Turkana, gaps and deficiencies in human and animal healthcare provision are location-specific (Table 4). We hypothesize that geographic differences (e.g. distance to the nearest health facility or hospital) or the existence of development programmes likely contributed to this observed variation. One major difference regarding challenges of vaccination between sectors was people refusing the vaccination, described by veterinarians (Table 5). Importantly, they described adding value with nonvaccination services (e.g. deworming) that help to improve vaccination coverage of livestock. This provides direct evidence that additional services increase the value of mobile outreach. This conclusion is supported by previous and ongoing integrated activities (e.g. Kimormor and the Karamoja exercise) and the perceived benefits of future activities identified by study participants (Table 6).

In most cases, participants addressed collaboration between government departments for zoonotic disease prevention and food safety, areas where veterinary medicine and public health have traditionally overlapped. Importantly, our study found that informal zoonotic disease reporting occurs between departments in Turkana County. The need for official reporting, however, is evident, especially considering the threat that zoonoses pose to pastoralists (Mangesho et al. 2017). Therefore, we suggest that improved disease reporting can be facilitated by the OHF. Specifically, subcounty officers can communicate at the subcounty $\mathrm{OHC}$ to either rapidly respond to disease outbreak events or report zoonotic disease cases to their superiors on the county $\mathrm{OHC}$ (Fig. 2). Importantly, this model has been adopted in Loima subcounty and has proven to be an effective measure to quickly respond to disease outbreak events. The creation of subcounty OHCs will formalize zoonotic disease reporting and can help to combat these diseases in Turkana County.

Our results highlight that animal health officials believe that joint zoonotic disease extension (ZDE) is best suited to explain the risks and prevention strategies 


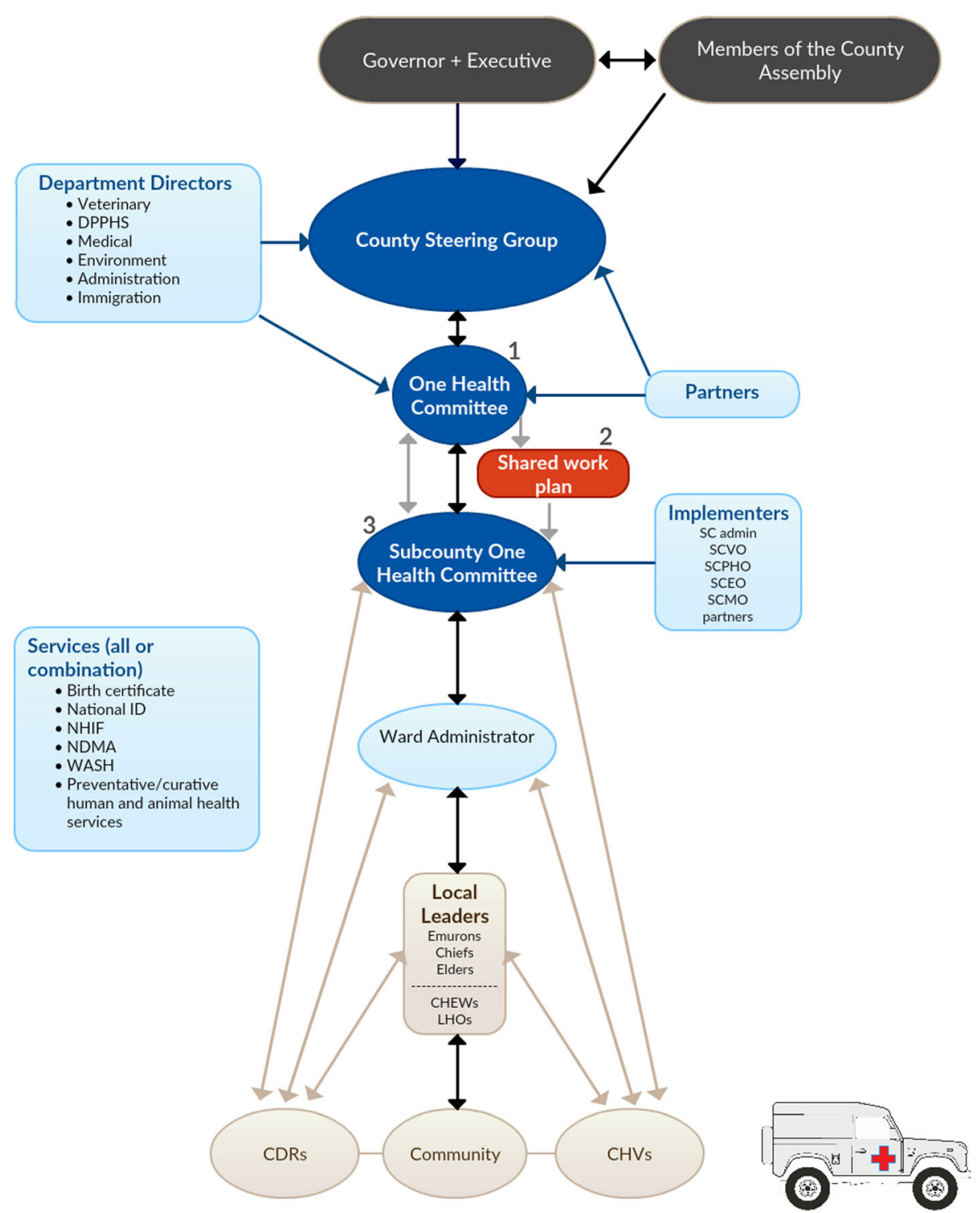

Fig. 2 A proposed One Health framework (OHF) for integrated service delivery. New components of service delivery are indicated by numbers: (1) One Health Committee $(\mathrm{OHC})$ at the county level made up of department directors and partners in the human and animal health sectors; (2) shared work plan created through intersectoral collaboration on the county $\mathrm{OHC}$; (3) subcounty $\mathrm{OHC}$ made up of subcounty officers (e.g. subcounty administrator, subcounty veterinary officer (SCVO), subcounty public health officer (SCPHO), subcounty environmental officer (SCEO), and implementing partners). Remaining officials and structures currently exist in Turkana. Arrows indicate suggested workflow of integrated service delivery and communication. Suggested services to be jointly delivered are listed

associated with these diseases to pastoralists. However, this type of extension is sporadic at best. Therefore, we recommend that joint ZDE, with both public health officials and veterinarians, should be adapted whenever possible in Turkana. This can be uniformly implemented through the use of shared work plans.

Our results suggest that the One Health approach is not limited to zoonoses and can be used to target the social determinants of health, through a One Health Huduma Centre. Previous research proves that better access to health services, without other social improvements to marginalized groups, may not have a positive impact on health (Abakar et al. 2016). Thus, improving access to public services in totality will improve health to a greater extent than simply focusing on health services.

In addition, the structure of the OHF is based on the county, subcounty, and ward administrative units and associated personnel that are generally uniform throughout Kenyan counties. Thus, this framework could be used in other ASAL counties in Kenya to improve the health of pastoralists. Furthermore, while not identical, similar 
administrative structures exist in other regions of subSaharan Africa with pastoralist populations. Therefore, the principles of the OHF (e.g. OHCs at the director and implementer levels and shared work plans for integrated activities) can be adopted and adapted to improve healthcare and other services for marginalized populations in these areas. Other non-pastoralist, resource-poor communities that lack access to public services in Kenya could also benefit from a similar approach.

Examples from Turkana, like Afya Timizia, illuminate how NGOs can conduct integrated service delivery. The principles of the OHF, e.g. shared work plans and coordination of activities throughout administrative levels, can be adopted by NGOs working in ASALs. We found that previous and current examples of integrated service delivery and intersectoral collaboration have contributed to a One Health landscape in Turkana. Our study establishes how interest and positive attitudes surrounding One Health and future intersectoral collaboration can be leveraged to institutionalize One Health, in this case through an innovative model that includes sharing of resources, joint planning, and implementation of activities.

Kenya is currently considering the 2019 Animal Health Bill (AHB) that would establish county One Health Committees (OHCs) consisting of animal, wildlife, medical, plant, and environmental health services. These committees are intended to address issues regarding zoonotic diseases, antimicrobial resistance, and response to any other "One Health" matter (Parliament of Kenya 2019). The OHF fits within the AHB but gives specific structures and recommendations for Turkana that will help to overcome service delivery constraints in the county and improve access to healthcare for Turkana pastoralists.

\section{Study limitations}

We only conducted four FGDs with pastoralists, a limitation of the study. Also, we failed to interview service providers in non-health sectors. Another limitation of our study was that we did not perform an economic analysis of our proposed model for service delivery.

\section{Conclusion}

In Turkana County, pastoralists and officials in the human and animal health sectors support integrated service delivery for a variety of reasons. Participants believe that integrated services will improve the overall access to animal and human healthcare, that cost-sharing among departments will keep integrated services affordable, and that such integration will increase community participation in health outreach events. Our proposed OHF provides a versatile and innovative method that may improve service provision as well as the health and livelihoods of pastoral communities in Turkana County,
Kenya. The OHF should be pilot tested, and outcomes should be evaluated, which may provide useful knowledge about the facilitators, barriers, and impacts of integrated multi-level service delivery within Turkana County and in pastoralist communities throughout subSaharan Africa.

\section{Recommendations}

We recommend that the Turkana CSG create a One Health strategic plan that delineates (1) a cooperation model-committees and hierarchy (i.e. OHF)-and (2) joint service delivery priorities-diseases, services, location, and timing. In light of the fact that the economic components of our described service delivery are unknown, we recommend a trial implementation period, during which all the costs and health/other outcomes are recorded. This will help to understand the economic and health implications of our proposed model of service delivery. We suggest the trial implantation focus on Loima and Turkana West subcounties that have remote locations that lack health facilities and have poor access to services.

\section{Abbreviations}

APaD: Agency for Pastoralist Development; ASALs: Arid and semi-arid lands; CBPP/CCPP: Contagious bovine and caprine pleuropneumonia;

CDRs: Community disease reporters; CDVS: County director of veterinary services; CHEWs: Community health extension workers; CHVs: Community health volunteers; COREQ: COnsolidated criteria for REporting Qualitative research; DPPH: Department of Preventative and Promotive Health; FAO: Food and Agriculture Organization of the United Nations; FGDs: Focus group discussions; FMD: Foot and mouth disease; IGO: Intergovernmental organizations; IRC: International Rescue Committee; LHA: Livestock health assistant; LWF: Luther World Federation; NDMA: National Drought Management Authority; NGO: Non-government organizations; NHIF: National Health Insurance Fund; OHC: One Health Committee; PE: Participatory epidemiology; PPR: Peste des petits ruminants; SCDSO: Subcounty disease surveillance officer; SCEO: Subcounty environmental officer;

SCPHO: Subcounty public health officer; SCVO: Subcounty veterinary officer; SSIs: Semi-structured interviews; TUPADO: Turkana Pastoralist Development Organization; VSF-Germany: Veterinaries sans Frontières-Germany;

WASH: Water, sanitation and hygiene

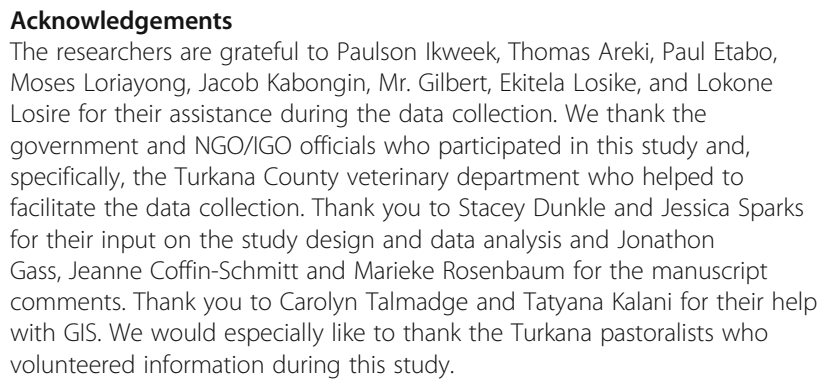
Moses Loriayong, Jacob Kabongin, Mr. Gilbert, Ekitela Losike, and Lokone Losire for their assistance during the data collection. We thank the government and NGO/IGO officials who participated in this study and, specifically, the Turkana County veterinary department who helped to facilitate the data collection. Thank you to Stacey Dunkle and Jessica Sparks for their input on the study design and data analysis and Jonathon Gass, Jeanne Coffin-Schmitt and Marieke Rosenbaum for the manuscript comments. Thank you to Carolyn Talmadge and Tatyana Kalani for their help with GIS. We would especially like to thank the Turkana pastoralists who volunteered information during this study.

\section{Relevant background (data collection)}

EFG is a DVM/MPH dual degree student with a Master of Science in Conservation Medicine with training and experience in participatory epidemiology methodology. JRK is a subcounty veterinarian in Turkana County with a Master of Science in Veterinary Preventive Medicine and extensive training and experience in participatory epidemiology methods. 


\section{Authors' contributions}

EFG, JRK, TK, and JCM designed and planned the study. TOA acted as an incountry mentor. EFG and JRK collected the data. EFG did the initial data analysis with help on the interpretation from other authors. EFG wrote the first draft of the manuscript with organizational help from HA, TK, and AHR. All authors edited and approved the final manuscript.

\section{Funding}

The study was funded by the Department of Infectious Disease and Global Health contingency funds at the Cummings School of Veterinary Medicine, Tufts University, USA.

\section{Availability of data and materials}

The datasets used/analysed during the current study are available from the corresponding author on reasonable request.

\section{Ethics approval and consent to participate}

The study was approved by the Social Behavioral \& Educational Research Institutional Review Board at Tufts University. It was granted exempt status. Prior to participation in the study, objectives and procedures of the research were explained to respondents and informed verbal consent was obtained. Community disease reporters (CDRs) fluent in English and local languages were used to interpret/translate during FGDs with pastoralists.

\section{Consent for publication}

Not applicable.

\section{Competing interests}

The authors declare that they have no competing interests.

\section{Author details}

'Cummings School of Veterinary Medicine, Tufts University, North Grafton, USA. ${ }^{2}$ Turkana County Government Directorate of Veterinary Services, Lodwar, Kenya. ${ }^{3}$ Department of Clinical Studies, Faculty of Veterinary Medicine, University of Nairobi, Nairobi, Kenya. ${ }^{4}$ Food and Agriculture Organization of the United Nations, Nairobi, Kenya.

Received: 14 November 2019 Accepted: 6 February 2020 Published online: 20 April 2020

\section{References}

Abakar, MF, E Schelling, M Béchir, BN Ngandolo, K Pfister, IO Alfaroukh, HM Hassane, and J Zinsstag. 2016. Trends in health surveillance and joint service delivery for pastoralists in West and Central Africa. The Future of Pastoralism (J. Zinsstag, E. Schelling \& B. Bonfoh, eds). Revue scientifique et technique (International Office of Epizootics) 35(2):683-691.

African Union. 2013. Policy framework for pastoralism in Africa: Securing, protecting and improving the lives, livelihoods and rights of pastoralist communities. AU, Department of Rural Economy and Agriculture.

Barrow, Edmund, and Hezron Mogaka. 2007. Kenya's drylands-Wastelands or an undervalued national economic resource. Nairobi: IUCN-The World Conservation Union.

Bomoi, I.M., N.E. Waziri, P. Nguku, and A. Tsofo. 2016. Integrated human and animal vaccination delivery to nomadic Fulani communities in northern Nigeria 2015. International Journal of Infectious Diseases 45: 22.

Charmaz, Kathy, and Linda Liska Belgrave. 2007. Grounded theory. In The Blackwell Encyclopedia of Sociology. New York: Blackwell Publishing.

Department of Health and Sanitation Services. 2018. Turkana County Government County Health Sector Strategic Plan 2018-2022. Lodwar, Kenya.

Desta, Angesom Hadush. 2016. One Health: An integrated approach for disease prevention and control in pastoral areas of Ethiopia. Journal of Health, Medicine and Nursing 22, 2422-8419.

El Shiekh, Babker, and Anke van der Kwaak. 2015. Factors influencing the utilization of maternal health care services by nomads in Sudan. Pastoralism 5 (1): 23.

Food and Agriculture Organization of the United Nations (FAO), Emergency Centre for Transboundary Animal Diseases, East Africa Region. 2009. The Impact of Peste des Petitis Ruminants (PPR) on Livelihoods in the Arid and Semi-arid Lands of Kenya: A case study of Turkana North District of Kenya, 2009. Nairobi, Kenya.
Kansiime, Catherine, Lynn M. Atuyambe, Benon B. Asiimwe, Anthony Mugisha, Samuel Mugisha, Victor Guma, Innocent B. Rwego, and Elizeus Rutebemberwa. 2015. Community perceptions on integrating animal vaccination and health education by veterinary and public health workers in the prevention of brucellosis among pastoral communities of South Western Uganda. PLoS One 10 (7): e0132206.

Kenya National Bureau of Statistics. 2010. Kenya population and housing census 2009. Government Printer Nairobi.

Kihu, Simon M., John M. Gachohi, Eunice K. Ndungu, George C. Gitao, Lily C. Bebora, Njenga M. John, Gidraph G. Wairire, Ndichu Maingi, Raphael G. Wahome, and Ricky Ireri. 2015a. Sero-epidemiology of Peste des Petits Ruminants virus infection in Turkana County, Kenya. BMC Veterinary Research $11(1): 87$.

Kihu, Simon M., George C. Gitao, Lily C. Bebora, Njenga M. John, Gidraph G. Wairire, Ndichu Maingi, and Raphael G. Wahome. 2015b. Economic losses associated with Peste des Petits Ruminants in Turkana County Kenya. Pastoralism 5 (1): 9.

Kimani, Tabitha, Margaret Ngigi, Esther Schelling, and Tom Randolph. 2016. One Health stakeholder and institutional analysis in Kenya. Infection Ecology \& Epidemiology 6 (1): 31191.

Kipronoh, Alexander Kipruto, Jackson Nyarongi Ombui, Henry Kimathi Kiara, Yatinder Singh Binepal, Eric Gitonga, and Hezron Okwako Wesonga. 2016 Prevalence of contagious caprine pleuro-pneumonia in pastoral flocks of goats in the Rift Valley region of Kenya. Tropical Animal Health and Production 48 (1): 151-155.

Lankester, Felix, Alicia Davis, Safari Kinung'hi, Jonathan Yoder, Catherine Bunga, Shayo Alkara, Imam Mzimbiri, Sarah Cleaveland, and Guy H. Palmer. 2019. An integrated health delivery platform, targeting soil-transmitted helminths (STH) and canine mediated human rabies, results in cost savings and increased breadth of treatment for STH in remote communities in Tanzania. BMC Public Health 19 (1): 1398

Mangesho, Peter Ernest, Moses Ole Neselle, Esron D. Karimuribo, James E. Mlangwa, Kevin Queenan, Leonard E.G. Mboera, Jonathan Rushton, Richard Kock, Barbara Häsler, and Angwara Kiwara. 2017. Exploring local knowledge and perceptions on zoonoses among pastoralists in northern and eastern Tanzania. PLoS Neglected Tropical Diseases 11 (2): e0005345.

Ministry of Agriculture, Livestock and Fisheries, Republic of Kenya. 2015. Kenya Veterinary Policy. State Department of Livestock, Nairobi, Kenya

Ministry of Health. 2014. Kenya Health Policy 2014-2030. Government of Kenya, Nairobi, Kenya.

Mocellin, Jérome, and Peter Foggin. 2008. Health status and geographic mobility among semi-nomadic pastoralists in Mongolia. Health \& Place 14 (2): $228-$ 242.

Munyua, Peninah M., M. Kariuki Njenga, Eric M. Osoro, Clayton O. Onyango, Austine O. Bitek, Athman Mwatondo, Mathew K. Muturi, Norah Musee, Godfrey Bigogo, and Elkanah Otiang. 2019. Successes and challenges of the one health approach in Kenya over the last decade. BMC Public Health 19 (3): 465 .

Nyariki, Dickson M., and Dorothy A. Amwata. 2019. The value of pastoralism in Kenya: Application of total economic value approach. Pastoralism 9 (1): 9.

Renault, Véronique, Haret A. Hambe, Guy Van Vlaenderen, Eddy Timmermans, Ahmed M. Mohamed, Olivier Ethgen, and Claude Saegerman. 2019. Economic impact of contagious caprine pleuropneumonia and cost-benefit analysis of the vaccination programmes based on a one-year continuous monitoring of flocks in the arid and semi-arid lands of Kenya. Transboundary and Emerging Diseases 66 (6): 2523-2536.

Schelling, Esther, Mahamat Bechir, Mahamat Abdoulaye Ahmed, Kaspar Wyss, Thomas F. Randolph, and Jakob Zinsstag. 2007. Human and animal vaccination delivery to remote nomadic families, Chad. Emerging Infectious Diseases 13 (3): 373

Schilling, Janpeter, Francis E.O. Opiyo, and Jürgen Scheffran. 2012. Raiding pastoral livelihoods: motives and effects of violent conflict in north-western Kenya. Pastoralism: Research, Policy and Practice 2(1): 25.

Kenya National Bureau of Statistics. 2019 Kenya population and housing census volume 1: Population by county and sub-county. Government Printer Nairobi.

Tong, Allison, Peter Sainsbury, and Jonathan Craig. 2007. Consolidated criteria for reporting qualitative research (COREQ): A 32-item checklist for interviews and focus groups. International Journal for Quality in Health Care 19 (6): 349-357.

Tullow Oil. 2017. Stakeholder engagement framework south Lokichar Basin, Turkana, Kenya. Tullow Oil, Nairobi, Kenya. 
Veterinary Services. 2019. Turkana County Government (Veterinary Services) 2019. Lodwar, Kenya.

Vesterinen, Heidi M., Tracey V. Dutcher, Kaylee M. Errecaborde, Michael W. Mahero, Katelyn W. Macy, Ong-Orn Prasarnphanich, Heidi Kassenborg, Erinaldi Yulizar, Rama P. Fauzi, and Nyoman S. Budayanti. 2019. Strengthening multi-sectoral collaboration on critical health issues: One Health Systems Mapping and Analysis Resource Toolkit (OH-SMART) for operationalizing one health. PLoS One 14 (7).

Ward, David E., Roger Ruppanner, Philippe J. Marchot, and Jørgen W. Hansen. 1993. One medicine-Practical application for non-sedentary pastoral populations. Nomadic Peoples: 55-63.

Weibel, Daniel, Esther Schelling, Bassirou Bonfoh, Jürg Utzinger, Jan Hattendorf, Mahamat Abdoulaye, Toguina Madjiade, and Jakob Zinsstag. 2008. Demographic and health surveillance of mobile pastoralists in Chad: Integration of biometric fingerprint identification into a geographical information system. Geospatial Health: 113-124.

Zinsstag, J., M.F. Abakar, M. Ibrahim, R. Tschopp, L. Crump, B. Bonfoh, and E. Schelling. 2016. Cost-effective control strategies for animal and zoonotic diseases in pastoralist populations. Revue scientifique et technique (International Office of Epizootics) 35 (2): 673-681.

Zinsstag, Jacob, M. Ould Taleb, and P.S. Craig. 2006. Health of nomadic pastoralists: New approaches towards equity effectiveness. Tropical Medicine \& International Health 11 (5): 565-568.

Zinsstag, Jakob, Esther Schelling, David Waltner-Toews, and Marcel Tanner. 2011. From "one medicine" to "one health" and systemic approaches to health and well-being. Preventive Veterinary Medicine 101 (3): 148-156.

Zinsstag, Jakob, Esther Schelling, David Waltner-Toews, Maxine Whittaker, and Marcel Tanner. 2015. One Health: the theory and practice of integrated health approaches. CABI.

Zoonotic Disease Unit: Strategic Plan for the Elimination of Human Rabies in Kenya 2014 - 2030. Nairobi: Ministry of Health and Ministry of Agriculture, Livestock and Fisheries; 2014.

\section{Publisher's Note}

Springer Nature remains neutral with regard to jurisdictional claims in published maps and institutional affiliations.

\section{Submit your manuscript to a SpringerOpen ${ }^{\circ}$ journal and benefit from:}

- Convenient online submission

- Rigorous peer review

- Open access: articles freely available online

High visibility within the field

- Retaining the copyright to your article

Submit your next manuscript at $\boldsymbol{\nabla}$ springeropen.com 